\title{
Antimicrobial Effects of the Combination of Chlorhexidine and Fluoride Varnish in Young Adult Population
}

\author{
KH Sumeera, Sylvia Mathew, Swaroop Hegde, BV Sreenivasa Murthy, John V George
}

\begin{abstract}
Aim: (1) Use of a cariogram to evaluate the caries risk assessment in the students. (2) To evaluate the effectiveness of chlorhexidine and fluoride varnish applications on Streptococcus mutans at a 3-month follow-up.

Materials and methods: All the students of first year BDS of MS Ramaiah Dental College were included in this study. Caries risk assessment was done using a Cariogram and the students were divided into moderate and low risk groups. Streptococcus mutans count was assessed at baseline for both the groups. Chlorhexidine and fluoride varnish application was done in the moderate risk group at an interval of 1 week. After a period of 3 months, the Streptococcus mutans count was determined for both the groups and the results statistically analyzed.
\end{abstract}

Results: A significant reduction in the Streptococcus mutans count in the moderate risk group was seen at a 3 month follow-up.

Conclusion: The combined use of both chlorhexidine and fluoride varnish applications reduced the oral Streptococcus mutans count to significantly low levels in the study group at the 3-month follow-up.

Keywords: Chlorhexidine varnish, Fluoride varnish, Streptococcus mutans, Dental caries.

How to cite this article: Sumeera $\mathrm{KH}$, Mathew $\mathrm{S}$, Hegde $\mathrm{S}$, Murthy BVS, George JV. Antimicrobial Effects of the Combination of Chlorhexidine and Fluoride Varnish in Young Adult Population. World J Dent 2012;3(4):290-293.

\section{Source of support: Nil}

Conflict of interest: None

\section{INTRODUCTION}

The conventional method of dealing with decay involves detection of the carious lesions, followed by drilling and filling. ${ }^{1}$ But it will most likely not prevent the lifelong continuation of the disease process and will allow recurrent decay necessitating further surgical intervention. ${ }^{2}$

There is now growing interest in utilizing models based at early disease prevention. M easures of caries control involve identifying the disease process and the risk factors. Caries risk assessment (CRA) is the process of collecting data regarding various factors (e.g. bacterial level) and indicators (e.g. previous caries experience) to predict caries activity in the immediate future. ${ }^{3}$

Cariogram is a caries risk predictor model that has been developed to describe and calculate the individual caries risk profile. ${ }^{4}$ This computer-based program indicates the chance an individual has of avoiding caries in the near future and expresses this graphically.

Caries progression, especially in its initial clinical stages, may be slowed down by the use of fluorides. Fluoride varnish enhances remineralization ${ }^{5}$ because the quantities of calcium and phosphate lost can be replaced in the form of fluorapatite. ${ }^{6}$

Isolated use of fluoride is insufficient to prevent progressive mineral loss and lesion formation. ${ }^{7}$ To control plaque formation and reduce its acidogenicity and to increase the possibility of remineralizing, some recommend the concomitant use of chlorhexidine. ${ }^{8}$ Chlorhexidine is a bisbiguanide and has been proved to be a potent chemotherapeutic agent against Streptococcus mutans ${ }^{9}$ with antibacterial, anticariogenic and remineralizing actions and few toxic effects. ${ }^{10,11}$ A variety of methods for delivering chlorhexidine in the form of mouthrinses, ${ }^{12}$ gels $^{13}$ or dentifrices ${ }^{14}$ has been tried. Chlorhexidine varnish was developed to prolong the contact with the teeth and to provide sustained release of the agent. ${ }^{15} \mathrm{The}$ application of a chlorhexidine varnish was successful in reducing oral $\mathrm{MS} \mathrm{S}^{16,17}$ and thus caries. ${ }^{18}$

Fluoride and chlorhexidine form a powerful combination: The fluoride acts to protect the hard tissues, while the chlorhexidine reduces bacterial pathogens in the saliva and dental plaque. ${ }^{19,20}$

Very few studies are available among the young adult Indian population which test the efficacy of the combined action of chlorhexidine and fluoride varnish application in reducing the Streptococcus mutans count.

\section{AIM OF THE STUDY}

1. Use of a Cariogram to evaluate the caries risk assessment in the students.

2. To evaluate the effectiveness of chlorhexidine and fluoride varnish applications on Streptococcus mutans at a 3-month follow-up.

\section{MATERIALS AND METHODS}

All the students of first year BDS, i.e. a total of 60 students were included in this study. W ritten informed consent was obtained from the students. They were examined and were interviewed at baseline about their general health, dietary 
Antimicrobial Effects of the Combination of Chlorhexidine and Fluoride Varnish in Young Adult Population

habits and use of fluoride supplements. Past caries experience was recorded based on the DM FT index. Plaque was assessed using Silness and Loe Plaque index ${ }^{21}$ followed by salivary examination.

\section{Salivary Examination}

Students were given clear instructions to refrain from eating 1 hour before the collection of saliva. They were asked to chew a block of paraffin wax for 5 minutes, and the accumulated saliva was collected into a sterilized measuring cup and was measured. One milliliter of saliva was transferred to a labelled sterile test tube containing $4 \mathrm{ml}$ of transport media (thioglycollate media) and immediately transported to the lab for processing. The saliva sample was serially diluted up to 10-3 dilutions using sterile saline $(0.85 \% \mathrm{NaCl}) \cdot 0.1 \mathrm{ml}$ of the suitable dilutions was aseptically plated onto pre-solidified mitis salivarius Bacitracin (M SB) agar for the cultivation of Streptococcus mutans and MRS agar for Lactobacillus respectively. A II the counts were reported as colony forming units per $\mathrm{ml}$. Lactobacillus count test was done only to obtain the caries risk assessment according to the Cariogram. The information was fed into the Cariogram software. Based on the Cariogram profiles, there were no students in the high risk group. The number of students in the low risk group were 30 and, in the moderate risk group, 26 in accordance with chance of avoiding caries. Four students left the course. The students in the moderate risk group were selected for chlorhexidine and fluoride varnish application.

\section{Chlorhexidine Varnish Application}

The teeth were isolated using cotton rolls and dried. A thin coat of varnish (Cervitec Ivoclar V ivadent) was applied by means of a suitable brush; in the proximal surfaces varnish was applied using floss and left for 30 seconds. The students were asked to refrain from eating and drinking for 3 hours and were recalled after a week for fluoride application.

\section{Fluoride Varnish Application}

A fter prophylaxis, teeth were dried but not isolated with cotton rolls as varnish being sticky has a tendency to stick to cotton. A total of 0.3 to $0.5 \mathrm{ml}$ of varnish (Duraphat) equivalent to 6.9 to $11.5 \mathrm{mg}$ fluoride was required to cover the full dentition. The application was done first on lower arch and then on upper arch with the help of single tufted brush starting with the proximal surface. The students were made to sit with their mouth open for 4 minutes before spitting to let varnish set on teeth. The students were asked to refrain from eating and drinking for 1 hour.
After a period of 3 months, the Streptococcus mutans count was determined for both the groups as previously mentioned and the results statistically analyzed.

\section{STATISTICAL ANALYSIS}

The statistical software namely SA S 9.2, SPSS 15.0, Stata 10.1, M edCalc 9.0.1, Systat 12.0 and $R$ environment ver. 2.11.1 were used for the analysis of the data. Descriptive statistical analysis has been carried out in the present study. Results on categorical measurements are presented in number (\%). Significance is assessed at $5 \%$ level of significance and $95 \%$ confidence interval. Student t-test (unpaired) was used to find the statistically significant difference between moderate and low risk and student t-test (paired) for significance between baseline and follow-up.

\section{RESULTS}

Table 1 and Figure 1 represent the comparative evaluation of Streptococcus mutans count in the both the risk groups, a significant reduction in the Streptococcus mutans count in the moderate risk group was seen at a 3-month follow-up.

\section{DISCUSSION}

Streptococcus mutans induces mineral loss due to its strong adhesion to the tooth surface and acid production resulting from the fermentation of carbohydrates, which keep local $\mathrm{pH}$ low. ${ }^{22}$ Therefore, reducing the levels of this microorganism in the oral cavity seems to be crucial for controlling caries.

A significant reduction in the Streptococcus mutans count was observed at the 3-month follow-up (see Table 1 and Fig. 1). A similar observation was made by Ogaard et al who showed that combined use of an antibacterial varnish and a fluoride varnish is more efficacious in averting new carious lesions. ${ }^{19}$

The use of fluoride varnish with chlorhexidine seems to create a favorable environment for remineralizing incipient lesions. ${ }^{23} \mathrm{Chlorhexidine} \mathrm{acts} \mathrm{by} \mathrm{damaging} \mathrm{the} \mathrm{cell}$ membrane of prokaryotes and by disrupting the cytoplasmatic constituents. Cell death occurs due to the rapid accumulation of metal ions inside the cells as they become more permeable. ${ }^{24}$ Its effectiveness is attributed to its substantivity, which is facilitated by its adsorption onto tooth surfaces, pellicle, plaque and mucous membranes. ${ }^{25} \mathrm{~W}$ ith a smaller drop in $\mathrm{pH}$ in plaque and the availability of fluoride ions released by the fluoridated varnish, there would be mineral replacement in the enamel in the form of fluorapatite. ${ }^{8}$ The combination of the two cariostatic agents 


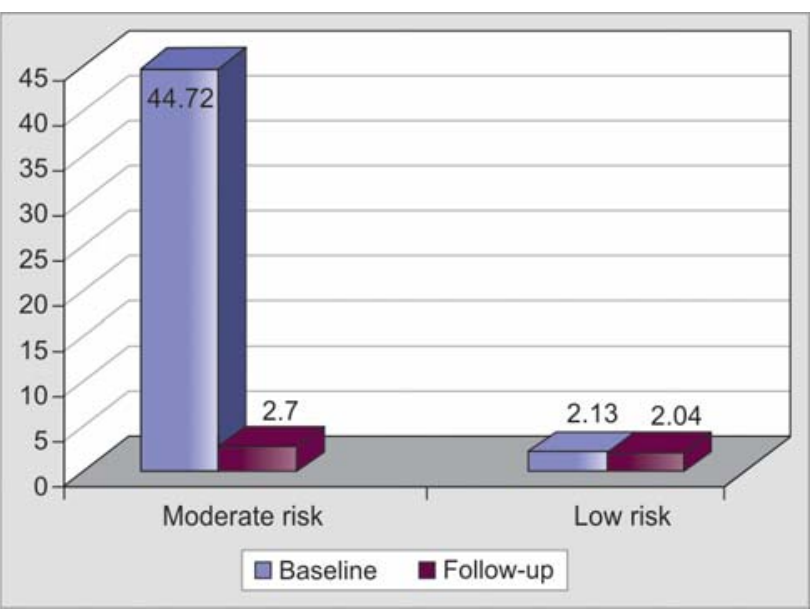

Fig. 1: Comparative evaluation of Streptococcus mutans count (CFU/ml) in moderate risk and low risk patients ( $\left.\times 10^{4} \mathrm{CFU} / \mathrm{ml}\right)$

Table 1: Comparative evaluation of Streptococcus mutans count $\mathrm{CFU}(\mathrm{CFU} / \mathrm{ml})$ in moderate risk and low risk patients $\left(\times 10^{4} \mathrm{CFU} / \mathrm{ml}\right)$

\begin{tabular}{llll}
\hline & Moderate risk & Low risk & p-value \\
\hline Baseline & $44.72 \pm 19.42$ & $2.13 \pm 1.42$ & $<0.001^{*}$ \\
Follow-up & $2.70 \pm 1.14$ & $2.04 \pm 1.43$ & $0.067^{+}$ \\
change(\%) & $93.9 \%$ & $3.75 \%$ & - \\
p-value & $<0.001^{* *}$ & 0.023 & - \\
\hline
\end{tabular}

+Suggestive significance ( $p$-value: $0.05<p<0.10$ ); *Moderately significant ( $p$-value: $0.01<p \leq 0.05$ ); **Strongly significant ( $p$-value: $p \leq 0.01)$

prevented the significant fall in $\mathrm{pH}$ than when the same substances were used individually. ${ }^{26}$ In addition, another in vivo research found that the combination resulted in less mineral loss from the enamel after 4 weeks of unaltered plaque accumulation, than the isolated use of fluoride or chlorhexidine. ${ }^{27}$

A nother study observed that a fluoride varnish (Fluor Protector) and flouride/chlorhexidine varnish (Cervitec) exerted prolonged antibacterial effect on $\mathrm{S}$. mutans and S. sobrinus biofilms. ${ }^{28} \mathrm{~A}$ systematic review on the effect of chlorhexidine on root caries concluded that chlorhexidine varnish may provide beneficial effects in patients in need of special care specifically in the absence of regular professional tooth cleaning and oral hygiene instructions. ${ }^{29}$

There are a few disadvantages with both these varnishes like bitter taste and some esthetical discomfort in anterior teeth due to the temporary peeling off of the varnish. ${ }^{30}$

Further studies involving a larger sample size and a longer follow-up period can give us a true picture about the efficacy of this combination therapy in an Indian scenario.

\section{CONCLUSION}

Within the limitations of the present study, it was observed that the combined use of both chlorhexidine and fluoride varnish applications reduced the oral Streptococcus mutans count to significantly low levels in the study group at the 3-month follow-up. Therefore, this treatment modality could be incorporated in our clinical practice as an effective method for controlling the caries risk especially for patients who fall under high or moderate risk of developing dental caries.

\section{ACKNOWLEDGMENT}

We deeply acknowledge the cooperation of all the students who consented to take part in the study. We extend our sincere thanks to $\mathrm{Dr}$ Suresh KP for helping us in the statistical analysis. We are grateful to M r A rijeet, Microbiologist, Genohelix Biolab, Bengaluru, for his support with the microbiological procedures.

\section{REFERENCES}

1. Fontana M , Zero DT. A ssessing patients caries risk. J A m Dent A ssoc 2006;137(9):123-19.

2. Kutsch V K, M ilicich G, D omb W, A nderson M, Zinman. How to integrate CA M BRA into private practice. J Calif Dent A ssoc 2007;35(11):778-85.

3. Hansel PG, Fure S, B ratthall D. Evaluation of a computer-based caries risk assessment program in an elderly group of individuals. A cta Odontol Scand 2003;61(3):164-71.

4. Hansel PG, Twetman S, B ratthall D. Evaluation of a computer program for caries risk assessment in schoolchildren. Caries Res 2002;36:327-40.

5. Seppä L, Hausen H, Tuutti H, Luoma H. Effect of sodium fluoride varnish on the progress of initial caries lesions. Scand J Dent Res 1983;91:96-98.

6. L ambrou D, L arsen M J, Fejerskov O, Tachos B. The effect of fluoride in saliva on remineralization of dental enamel in humans. Caries Res 1981;15:341-45.

7. Luoma H, M urtomaa H, N uuja T, et al. A simultaneous reduction of caries and gingivitis in a group of school children receiving chlorhexidine-fluoride applications. R esults after 2 years. Caries Res 1978;12:290-98.

8. K atz S. The use of fluoride and chlorhexidine for the prevention of radiation caries. J A m D ent A ssoc 1982;104:164-70.

9. Fardal 0 , Turnbull RS. A review of the literature on use of chlorhexidine in dentistry. J A mer Dent Assoc 1986;112: 863-69.

10. Petti S, Hausen H. Caries-preventive effect of chlorhexidine gel applications among high-risk children. Caries Res 2006;40:514-21.

11. Rodrigues $C R, M$ arquezan $M, B$ arroso $L P$, et al. Effect of chlorhexidine-thymol varnish on caries lesion development in first permanent molars. J Clin Dent 2008;19:18-21.

12. Emilson CG, W estergren G. Effect of chlorhexidine on the relative proportions of Streptococcus mutans and Streptococcus sanguis in hamster plaque. Scan J Dent Res 1979;87:288-95.

13. Zickert I, Emilson CG, V rasse B. Effect of caries preventive measures in children highly infected with the bacterium Streptococcus mutans. A rch Oral Biol 1982;27:861-68.

14. Emilson CG, Fornell J. Effect of tooth brushing with chlorhexidine gel on salivary microflora, oral hygiene and caries. Scan J Dent Res 1976;84:308-19.

15. Balanyk TE, Sandham HJ. Development of sustained-release antimicrobial dental varnishes effective against Streptococcus mutans in vitro. J Dent Res 1985;64:1356-60. 
16. Schaeken M J, Schouten MJ, V an D en K ieboom CW, V an Der Hoeven JS. Influence of contact time and concentration of chlorhexidine varnish on mutans Streptococci in interproximal dental plaque. Caries Res 1991;25(4):292-95.

17. Ie $Y L$, Schaeken MJ. Effect of single and repeated application of chlorhexidine varnish on mutans Streptococci in plaque from fissures of premolar and molar teeth. Caries Res 1993;27(4): 303-06.

18. A raujjo AM , Naspitz GM , Chelotti A, Cai S. Effect of Cervitec on mutans Streptococci in plaque and on caries formation on occlusal fissures of erupting permanent molars. Caries Res 2002;36(5):373-76.

19. Ogaard B, Larsson E, Henriksson, Birkhed T, Bishara D SE. Effects of combined application of antimicrobial and fluoride varnishes in orthodontic patients. A m J Orthod Dentofacial Orthop 2001;120(1):28-35.

20. Derks A, Frencken J, B ronkhorst E, K uijpers-Jagtman A M, $K$ atsaros $C$. Effect of chlorhexidine varnish application on mutans Streptococci counts in orthodontic patients. A m J Orthod Dentofacial Orthop 2008;133(3):435-39.

21. Sillness ], L oe H. Periodontal disease in pregnancy. Correlation between oral hygiene and periodontal condition. Acta Odont Scand 1964;22:21-35.

22. Banas JA, Miller JD, Fuschino ME, et al. Evidence that accumulation of mutants in a biofilm reflects natural selection rather than stress-induced adaptive mutation. Appl Environ Microbiol 2007;73:357-61.

23. De A morim RG, Leal SC, BarretoBezerra AC, De A morim FPLG, De Toledo OA. International Journal of Paediatric Dentistry 2008;18:446-51.

24. M odesto A, DrakeDR. M ultiple exposures to chlorhexidine and xylitol: Adhesion and biofilm formation by Streptococcus mutans. Curr M icrobiol 2006;52:418-23.

25. Bonesvoll P, Lokken P, Rolla G, Paus PN. Retention of chlorhexidine in the human oral cavity after mouthrinses. A rch Oral Biol 1974;19:209-12.

26. M CD ermid A S, M arsh PD, K eevil CW, Ellwood DC. A dditive inhibitory effects of combinations of fluoride and chlorhexidine on acid production by Streptococcus mutans and Streptococcus sanguis. Caries Res 1985;19:64-71.

27. Ullsfoss BN , O gaard B, A rends J, Ruben J, Rölla G, A fseth J. Effect of a combined chlorhexidine and $\mathrm{NaF}$ mouthrinse: $\mathrm{A} n$ in vivo human caries model study. Scand J Dent Res 1994;102: 109-12.

28. Erdem AP, Sepet E, G üvenK ul ekci, Trosola SC, Y eganeG uven. Effects of two fluoride varnishes and one fluoride/chlorhexidine varnish on Streptococcus mutans and Streptococcus sobrinus biofilm formation in vitro. Int J M ed Sci 2012;9:129-36.

29. Slot DE, V aandrager NC, Loveren CV, V an Palenstein Helderman WH, $\mathrm{V}$ an der W eijden $\mathrm{GA}$. The effect of chlorhexidine varnish on root caries: A systematic review. Caries Res 2011;45:162-73.

30. Schaeken M J, Schouten M J, V an D en K ieboom CW, V an Der Hoeven JS. Influence of contact time and concentration of chlorhexidine varnish on Streptococci mutans in interproximal dental plaque. Caries Res 1991;25(4):292-95.

\section{ABOUT THE AUTHORS}

\section{KH Sumeera (Corresponding Author)}

Postgraduate Student, Department of Conservative Dentistry and Endodontics, M S Ramaiah Dental College, M SR IT Post, M athikere B engal uru-560054, K arnataka, India, Phone: (0)9886339314 e-mail: sumeera.hussain@yahoo.com, sumeerahussain@ gmail.com

\section{Sylvia Mathew}

Professor and Head, Department of Conservative Dentistry and Endodontics, M S Ramaiah D ental College, B engaluru, K arnataka, India

\section{Swaroop Hegde}

Professor, Department of Conservative Dentistry and Endodontics MS Ramaiah D ental College, B engaluru, Karnataka, India

\section{BV Sreenivasa Murthy}

Professor and Principal, Department of Conservative Dentistry and Endodontics, MS Ramaiah Dental College, Bengaluru, Karnataka India

\section{John V George}

Professor, Department of Conservative Dentistry and Endodontics MS Ramaiah D ental College, B engaluru, Karnataka, India 